\title{
GRANDES Y PEQUEÑOS GANADEROS TRASHUMANTES EN LAS SIERRAS SORIANAS EN EL TRANSITO DE LA EDAD MEDIA A LA MODERNA
}

\author{
MAXIMO DIAGO HERNANDO \\ Universidad de Colonia
}

\section{RESUMEN}

Se trata de llamar la atención en este artículo sobre el papel de primera fila que jugaron los grandes señores de ganados en la actividad ganadera trashumante en el ámbito que abarcaba la cuadrilla mesteña de Soria durante los siglos xv y XVI. Para ello se establecen comparaciones entre el tamaño de sus rebaños y los de otros medianos y pequeños propietarios de la región, teniendo en cuenta entre otros indicios las noticias sobre sus ventas de lanas. Al mismo tiempo se profundiza en su caracterización desde el punto de vista sociopolítico, matizando algunas hipótesis que se han venido manejando para definir la base social mesteña y su evolución a lo largo del siglo xvi. Y por fin se repasan algunos aspectos referentes a la gestión de las explotaciones ganaderas trashumantes, que revelan la presencia de numerosos factores que hacían más rentables a las grandes frente a las medianas y pequeñas.

\section{ABSTRACT}

Big sheep owners played a key role in nomadic sheeprearing in the Spanish region around Soria during the xvth. and xvith. centuries. By using the volume of wool sales, the author compares the size of their flocks with those of other middle and small owners in the region and analyzes the owners' sociopolitical profile, in order to qualify traditional hypotheses about the social basis of the «Mesta» and its evolution during the xvith. century. Lastly, some aspects of the management of sheeprearing enterprises are examined, and its factors identified. In particular, the analyses focuses on those aspects of sheeprearing that made big enterprises more profitable than small ones.

La caracterización de la base social de la Mesta en las diferentes etapas de su historia, pese a haber sido ya abordada por muy diversos y prestigiosos investigadores, sigue representando un problema historiográfico muy imperfectamente resuelto, por falta de estudios monográficos que profundicen en la identificación de los ganaderos mesteños. 
A grandes rasgos, algunos autores han querido establecer una radical distinción entre ganaderos serranos, entre los que predominarían pequeños propietarios de rebaños, y ganaderos riberiegos, que representarian a los grandes propietarios por antonomasia, los cuales a raíz de su entrada en la Mesta por efecto de la concordia de 1566 habrían desvirtuado radicalmente el carácter de esta institución, de forma que en palabras de Carande lo que pudo haber sido una democracia de pastores degeneró en oligarquía de ganaderos 1 .

En concreto, por lo que se refiere al caso de las sierras de Soria, llama la atención advertir cómo prestigiosos investigadores no han dudado en caracterizar el panorama que éstas presentaban a fines de la Edad Media y comienzos de la Edad Moderna como el propio de una idilica democracia pastoril, cuando la práctica totalidad de la documentación disponible para la reconstrucción de la historia soriana en esta época se encontraba hasta la actualidad inexplorada 2 . De hecho la historiografía local por el contrario, no por estar más en contacto con la documentación sino por tener más asumidos los tópicos de la tradición soriana, nunca sostuvo que hasta el final del Antiguo Régimen fuesen los pequeños propietarios los que imprimieron carácter a la ganadería trashumante practicada en la región, sino que por el contrario insistió en presentar la dedicación a la trashumancia como una actividad propia de hidalgos de elevada posición, y la dedicación a la ganadería estante como actividad que únicamente interesó a los campesinos pobres 3 .

Advirtiendo, pues, la falta de fundamentación en datos empíricos contrastables de todas estas tesis, y la propia existencia de contradicciones entre ellas, hemos querido por consiguiente en el presente trabajo profundizar en el análisis de las explotaciones ganaderas trashumantes del ámbito soriano en el tránsito de la Edad Media a la Moderna a fin de determinar, con el mayor aporte documental posible, el grado de veracidad de las principales tesis hasta ahora manejadas para caracterizar la base social mesteña en el conjunto del reino de Castilla en general y en el ámbito de la cuadrilla soriana en particular. $Y$ hemos optado por escoger el referido período cronológico por tratarse de una época en que, según autores clásicos como Carande o Ruiz Martín, entró en crisis el modelo mesteño basado en el dominio de los pequeños propietarios serranos para dar paso a uno de carácter más marcadamente oligárquico

1 Vid. Carande (1987), t. I, pp. 79-80.

2 Vid. Carande (1987), t. II, pp. 529-30. Refiriéndose al ámbito soriano, en la década de 1540 apunta que «Cabe pensar alli en un tipo de bienestar uniforme, entre los muchos pastores de sus tierras..... Aunque sin referirse expresamente al caso soriano también propone un panorama semejante para el periodo 1450-1526 Ruiz Martín (1974), pp. 275 y ss.

3 Vid. Rabal (1980), pp. 474 y ss. 
en el que el protagonismo correspondió a los grandes propietarios, avecindados en su mayoría en ciudades de la submeseta sur, y cada vez más en Madrid.

\section{EVOLUCION DEL PERFIL SOCIOPOLITICO DE LOS GANADE- ROS TRASHUMANTES SORIANOS ENTRE LOS SIGLOS XV Y XVI}

Los datos cuantitativos sobre tamaño de los rebaños o volumen de lanas vendidas por los ganaderos son muy escasos en las fuentes documentales sorianas del siglo $\mathrm{XV}$, pero a pesar de su escasez permiten constatar la existencia en la zona de grandes propietarios de variada condición social, entre los que se encuentran desde representantes de la alta nobleza hasta simples hidalgos rurales 4 .

Miembros de las oligarquias de los concejos de realengo, y en particular del de Soria, figuraban por supuesto entre estos propietarios de grandes rebaños, pero no todos participaron de esta condición, y por regla general ninguno prodigó su participación personal en las instituciones mesteñas, delegando a lo sumo esta tarea en sus mayordomos y mayorales 5 . Por el contrario todas las noticias sugieren que el control de la cuadrilla soriana de la Mesta en el siglo XV estuvo en manos de familias ganderas de aldeas serranas de la Tierra de Soria, entre las que destacaba Gallinero, y de Yanguas, cuyos miembros no pasaban de ser simples hidalgos o incluso en algunos casos pecheros acomoda$\operatorname{dos} 6$.

4 Vid. Diago (1990a), pp. 554-557. Entre los representantes de la alta nobleza figuran los condes de Medinaceli, que en 1435 tenían un rebaño de ovejas trashumantes de algo más de 2.000 cabezas, contando corderos. Los condes de Monteagudo tenian cerca de 3.000 cabezas de ganado trashumante en 1505, además de 1.318 ovejas churras estantes. No hay datos precisos sobre los condes de Aguilar, señores de Yanguas y Cameros, pero a mediados del xvi se les llegó a atribuir la posesión de 25.000 cabezas. Entre los representantes de la nobleza media u oligarquías urbanas destaca Rodrigo de Vera, señor de Hinojosa de la Sierra, con varios rebaños que supera. rian las 9.000 cabezas. Entre los hidalgos rurales hay que destacar a Ruy Diaz de Fuenmayor, vecino de la pequeña aldea serrana de Santa Cruz de Yanguas, quien en 1469 poseía 1.945 cabezas mayores, 1.160 carneros y algo más de 500 corderos. Por su parte, Mari Garcia de las Heras, hija de un ganadero yangüés casada con otro ganadero de Gallinero, aldea de la Tierra de Soria, poseía en 1513 , año de su muerte, 4.000 ovejas y 133 vacas trashumantes.

s Datos sobre familias de la oligarquía soriana del $x v$ que fueron importantes propietarios de rebaños trashumantes y otras que no lo fueron en Diago (1990a), pp. 490-491, y (1993b).

- Referencias al funcionamiento institucional de la cuadrilla soriana de la Mesta durante el reinado de los Reyes Católicos en Diago (1990a), pp. 346-349. En estos años los ganaderos sorianos que desempeñaban un papel más destacado en la Mesta eran Antón del Río, vecino todavía de Yanguas, y sus cuñados Juan de Vinuesa, vecino de Gallinero, y Diego González de Castejón, vecino de Agreda. Relación de oficiales elegidos por la cuadrilla mesteña de Soria entre 1498 y 
Esta constatación vendría, pues, a primera vista a corroborar la tesis de quienes sostienen que fueron pequeños ganaderos asentados en ámbitos rurales de las sierras castellanas de los sistemas Ibérico y Central quienes imprimieron su carácter a la institución mesteña en época medieval. Pero un análisis más en profundidad de los datos disponibles para el caso soriano nos lleva sin embargo a concluir en un sentido completamente opuesto, dado que resulta fácil comprobar cómo estas familias ganaderas serranas que aparecen representando a la cuadrilla mesteña soriana en el siglo XV eran ya entonces propietarias de grandes rebaños, y comenzaban a disfrutar de una posición económica muy destacada, que no guardaba relación con su rango sociopolítico, muy modesto en relación con el de los miembros de la oligarquía urbana de Soria.

Significativamente, por otra parte, estas mismas familias continuaron monopolizando la representación soriana en la Mesta durante todo el siglo XVI, pero para entonces sus principales representantes ya habian alcanzado un rango sociopolítico notablemente superior, habiéndose convertido en regidores de Soria y Agreda, e incluso en destacados señores de vasallos 7 .

Junto a estas afortunadas familias de grandes ganaderos, que con su dedicación a la trashumancia sentaron las bases para un proceso de promoción sociopolítica a lo largo del siglo XvI sin paralelos en la historia soriana, coexistieron en los ámbitos serranos ya en el siglo $\mathrm{XV}$ otros múltiples pequeños ganaderos $^{8}$, y sobre todo mayorales, pastores y zagales, que servían a señores de ganados avecindados tanto en los núcleos rurales serranos como en las ciudades de Soria y Agreda, y que por supuesto también poseían sus propios modestos rebaños 9 .

Por consiguiente eran muchos los que ganaban su sustento con la ganadería trashumante en las sierras sorianas tanto en el siglo XV como en el XVI, en notable contraste con las tierras llanas, donde los campesinos sólo se dedica-

1521, Ibid., pp. 552-553. Además de los 3 individuos ya citados, destacan otros pertenecientes a familias de Gallinero (Neilas y Calderones) y Vinuesa (García de Sevilla y Montenegro). Precisamente estas dos últimas familias consta que tenian origenes pecheros.

7 Estos fenómenos quedan muy bien ilustrados en el seguimiento de la trayectoria de las familias Vinuesa, Ríos y Castejones, minuciosamente analizada en Diago (1993b).

${ }^{8}$ Entre otras pruebas documentales que demuestran la existencia de pequeños ganaderos trashumantes en el xv, vid., por ejemplo, contratos de ventas de lanas de 24-IX-1443 concertados por varios vecinos de La Losilla con el escribano soriano Juan Rodríguez de Soria en AHN, Osuna, leg. 2244-10-9, pieza 20. La cantidad de arrobas que se compromete a entregar respectivamente cada vecino es: $100,6,30,60,28,8,12$ y 6 . También se dispone de referencias documentales sobre la compra de lanas por judios sorianos a pastores serranos, entre ellos vasallos del duque de Najera. Vid. Diago (1989), pp. 35 y ss.

${ }^{9}$ Son múltiples los datos sobre el avecindamiento en estos ámbitos de la mayoría de los mayorales y pastores. En las ordenanzas de Vinuesa de 1504 se reconoce que muchos vecinos se iban a vivir con amos de otros lugares para guardarles sus ganados. 
ban a la cría de ganado ovino estante o, en el caso de los más hacendados, transterminante, que era llevado a pastar en invierno a las vecinas tierras de Navarra y Aragón ${ }^{10}$. Pero también es cierto que las diferencias de riqueza entre los distintos ganaderos transhumantes serranos eran enormes, y que por lo tanto esa imágen de «bienestar uniforme» que para las tierras sorianas de la primera mitad del XVI sugiere Carande es falsa, y muy en particular si la aplicamos a las aldeas volcadas a la ganadería trashumante ${ }^{11}$. Las propias diferencias de riqueza en el seno del grupo de los ganaderos autónomos, y entre éstos y sus pastores, asi lo confirman, pero por otro lado hay que tener en cuenta también que hasta cierto punto los sectores de la población rural serrana que participaban de los beneficios de la trashumancia representaban a los privilegiados, puesto que junto a ellos coexistian otros muchos campesinos desprovistos de ganados propios, que se ganaban la vida mediante la dedicación a la arrieria o en la industria de fabricación de paños. $Y$ asi lo demuestran las numerosas noticias de los protocolos notariales del XVI que presentan a vecinos de aldeas serranas comprando lana «churra», procedente del esquile del ganado estante, a mercaderes tanto de la ciudad de Soria como de la villa de Yanguas ${ }^{12}$. Y no cabe duda de que éstos se debian desenvolver en una situación económica sumamente precaria, si tenemos en cuenta que las condiciones climáticas y edafológicas de las comarcas serranas no les permitían complementar adecuadamente los ingresos derivados de su actividad artesanal con el cultivo de tierras de cereal que les asegurase el sustento en épocas de dificultad 13 .

Pero dejando a un lado el ámbito estrictamente serrano, no hay que olvidar que en los núcleos urbanos de Soria y Agreda ya habia asentados en el siglo XV numerosos señores de ganados, y que con el paso del tiempo tendieron a avecindarse en ellos la mayoría de los máximos propietarios ganaderos procedentes de los ámbitos rurales serranos, de forma decidida a partir de las primeras décadas del XVJ ${ }^{14}$. La valoración cuantitativa de este trasvase de grandes señores de ganados desde ámbitos rurales a los principales núcleos urbanos de la región soriana resulta de momento inabordable, pero los indicios documentales son suficientes para, en este punto, confirmar la tesis del

10 Vid. Diago (1990a), pp. 469-470.

11 Cf. nota 2.

12 Vid. Diago (1992).

13 Vid. memoriales que dan cuenta de la situación económica de Yanguas a principios del xvi en AChV, PC, Taboada, F, envoltorio 170-27.

14 Cf. nota 7. Más noticias sobre avecindamientos de ganaderos procedentes de tierras del conde de Aguilar en Agreda en Diago (1990a), pp. 478-479. Sobre avecindamientos en Soria, Ibid. pp. 481-483. 
profesor Ruiz Martín según la cual en ciudades como León, Cuenca, Segovia o Soria fue a partir de la tercera década del xvi cuando la figura del señor de ganados alcanzó su plenitud, sumando grandes rebaños a los de los serranos auténticos para mantener el contingente ovino trashumante en un nivel que, a pesar de todo, se iba reduciendo con respecto al de época medieval ${ }^{15}$. No obstante, no hay que desvirtuar la significación de este fenómeno presentándolo como un testimonio de la crisis de la auténtica ganadería serrana, puesto que, ateniéndonos al caso soriano, se puede demostrar que la mayoria de estos grandes señores de ganados del XVI asentados en Soria y Agreda procedían de villas o aldeas de la sierra, en las que se había iniciado el proceso de enriquecimiento de sus familias gracias a su dedicación a la ganadería, de forma que su cambio de vecindad no representó sino un paso más en su carrera de promoción sociopolitica. Además no hay por qué establecer una radical diferenciación entre ganaderos de aldeas serranas y ganaderos de núcleos urbanos de piedemonte, como Soria o Agreda, cuando estos últimos eran cabeceras de ámbitos jurisdiccionales que englobaban extensos terrenos de pasto, generalmente localizados en comarcas serranas, que podian ser aprovechados en igualdad de condiciones tanto por sus vecinos como por los de las aldeas sometidas a su jurisdicción ${ }^{16}$.

A tenor de todo lo dicho se puede concluir por consiguiente que el principal cambio en la conformación sociopolítica del grupo de ganaderos trashumantes sorianos en el tránsito de la Edad Media a la Moderna no radicó tanto en la pérdida de protagonismo de los modestos ganaderos serranos en favor de un nuevo tipo de señor de ganados urbano, representante según algunos de una burguesía ganadera ${ }^{17}$, sino más bien en la renovación de las oligarquías

15 Ruiz Martin (1974), p. 279.

16 Análisis comparativo sobre el diferente régimen de regulación de aprovechamiento de pastos en tierras de Soria y Segovia en Diago (1990a), pp. 278 y ss. Sobre diferencias que se observan dentro del ámbito soriano entre unas comunidades de villa y Tierra y otras, Ibid., pp. 475 y ss.

17 Cf. nota 15. El término «burguesia ganadera» lo emplea López Salazar (1987), p. 145. Sostiene que las dehesas maestrales fueron aprovechadas en el siglo xvi por una burguesía ganadera, ennoblecida o no, muy pudiente y ligada al patriciado urbano de Cuenca y Molina. Dado que la documentación que él utiliza se refiere al Campo de Calatrava sus conclusiones no afectan a la caracterización de los ganaderos sorianos, que apenas estuvieron presentes en este ámbito, concentrándose en contrapartida en las dehesas de la mesa maestral de Alcántara en La Serena. No obstante, consideramos que no se debe caracterizar a los grandes señores de ganados sorianos del xvi como «burgueses», pues tanto por su origen social como por su modo de vida no participaban de los rasgos propios de la «burguesia». López Salazar de hecho caracteriza a Marcos de Madrid, quien en 1542 se hizo cargo del arrendamiento de la mesa maestral de Calatrava, como digno representante de la burguesía castellana del XVI (p. 84). Nosotros, por nuestra parte, pensamos que Antón del Rio, quien ese mismo año se hizo cargo del arrendamiento de la mesa maes- 
de los dos principales concejos de realengo de la región, Soria y Agreda, mediante la incorporación de familias ganaderas hasta entonces marginadas en ámbitos rurales ${ }^{18}$, y el establecimiento de alianzas matrimoniales por parte de las viejas familias de caballeros integrantes de dichas oligarquias con las nuevas familias de ganaderos enriquecidos ${ }^{19}$.

\section{IDENTIFICACION DE GRANDES, MEDIANOS Y PEQUEÑOS GANADEROS DEL XVI A PARTIR DE LAS NOTICIAS DE CONTRATOS DE VENTAS DE LANAS}

Con excepción de un contrato atípico del año 1555 en el que se vendieron 6.829 arrobas de lana extremeña a 900 mrs. y 766 arrobas de aninos a 725 mrs. ${ }^{20}$, los contratos de mayor cuantía concertados por ganaderos sorianos de forma individual, aunque con frecuencia incluyendo también las lanas de sus criados y aparceros, rondaban las 4.000 arrobas, sin incluir aninos. $Y$ fueron precisamente ganaderos de las familias Ríos, Vinuesas y Castejones quienes pusieron a la venta estas cantidades máximas, que en principio sólo se podian reunir mediante el esquile de una cabaña que contase con en torno a 20.000 cabezas, admitiendo, según valoraciones de la época, que se necesitaban 6 ovejas ó 5 carneros para reunir una arroba de lana ${ }^{21}$.

tral de Alcántara (vid. Carande, t. II, pp. 395-396), y a la vez presenta muchos paralelismos con la figura de Marcos de Madrid, era ante todo un digno representante de la nobleza media soriana, como señor de vasallos y descendiente de hidalgos que habian estado varias generaciones al servicio de los señores de Cameros. Cf. nota 7 . No entramos a valorar los casos de Molina y Cuenca, que desconocemos.

18 Vid. Diago (1993b).

19 Los datos sobre estas alianzas son numerosos y su relación resulta excesivamente prolija Algunos son analizados en Diago (1990a). Entre las alianzas más desiguales hay que destacar la de los Alvarez de Calatañazor, linaje de rancio abolengo presente en el regimiento soriano durante gran parte del siglo $\mathrm{xV}$ pero de posición económica modesta y sin vinculación con la ganaderia trashumante, con los García de Sevilla, ganaderos de Vinuesa de origen pechero.

20 Vid AHPS, PN, 5-14, 16-IX-1555. Cristóbal de Salazar, vecino de Soria, habia vendido al duque de Nájera y a dos vecinos de Nájera en su nombre 6.829 arrobas de lana extremeña a 900 mrs., 766 arrobas de aninos extremeños a 725 y 380 arrobas de lana basta a 725 mrs. Doce ganaderos de Lumbreras, Villoslada y Ortigosa, lugares de señorio del duque de Nájera, se obligan a pagar a Cristóbal de Salazar $6.976 .950 \mathrm{mrs}$. por las referidas lanas. Por todas estas razones el referido contrato presenta unas caracteristicas totalmente atípicas, y no alcanzamos a explicar que realidad subyace tras el mismo. Tampoco hemos logrado resolver con satisfacción la identificación de Cristóbal de Salazar, alcalde mayor de sacas del obispado de Osma.

21 El dato sobre la equivalencia entre arrobas y cabezas lo tomamos de la averiguación de cuentas sobre el rendimiento de una cabaña de 3.000 cabezas perteneciente a Maria de Castejón a partir del año 1517, en AChV, PC, Pérez Alonso F. C. 1.082-1. También se indica en estas cuentas que se necesitaban 18 corderos para reunir una arroba de aninos. Carande establece una 
Por debajo de estos «magnates ganaderos», que ocupaban un lugar de primera fila en las oligarquías de Soria y Agreda desde mediados del siglo XvI, aparecen también en los protocolos notariales otros vendedores de cantidades de lana relativamente elevadas, superiores en todos los casos a 1.000 arrobas, varios de los cuales, aunque mantenían estrechos vinculos familiares con las referidas oligarquias urbanas, tenían fijada su residencia en aldeas strranas de la Tierra de Soria, algunas de las cuales todavia siguen reflejando en la actualidad en sus hermosas casas solariegas la riqueza de sus vecinos de antaño ${ }^{22}$.

No se habia producido por consiguiente en el transcurso del siglo XVI una total concentración de grandes señores de ganados en las ciudades de Soria y Agreda, donde no obstante si se habian avecindado los mayores, sino que también en pequeñas aldeas serranas y en las villas señoriales de Yanguas y San Pedro Manrique se podían encontrar propietarios de muy nutridos rebaños, aunque era más frecuente que en estos ámbitos residiesen medianos y pequeños propietarios y una interminable cohorte de mayorales, pastores y zagales que les servian a ellos y a los grandes propietarios urbanos. Por lo demás los pocos grandes propietarios que residian en ámbitos rurales frecuentemente lo hacian sólo en calidad de moradores y disfrutaban de la condición de vecinos

equivalencia entre 5 ovejas y una arroba (t. I, p. 112), mientras otros autores proponen la cifra más improbable de 10 ovejas por arroba. Vid. Córdoba de la Llave (1989) y Argente del Castillo (1991), p. 209. Entre los contratos más sobresalientes se pueden destacar: Juan de Vinuesa, regidor de Soria, vende en 1571 a mercaderes burgaleses 4.224 arrobas de lana y 1.233 de aninos por 700 mrs., Vid. AChV, PC, Quevedo, F. C. 177-3. Otros muchos datos sobre ventas de lanas de gran envergadura efectuadas por este regidor en diversos años a partir de 1545 , que no informan, sin embargo, sobre las cantidades de arrobas entregadas en cada contrato, sino sobre las cantida. des debidas por los mercaderes compradores (en un contrato se alcanza la cifra máxima de 11.740.455 mrs. que se comenzarian a cobrar a partir de 1563), en AChV, PC, Z. y Walls, F. C. 585-1. Martin González de Castejón, vecino de Agreda y señor de Velamazán, vendió a un mercader de Pamplona 4.000 arrobas de lana y 426 de aninos a 758,5 mrs. Vid. AHPS, PN, C. 15012250, 9-X-1570. Alonso de Río, regidor de Soria, vendió en 15834.000 arrobas de lana a mercaderes de Najera. AHPS, PN, 86-194, 27-VII-1583. Al año siguiente vendió 3.500 arrobas a mercaderes burgaleses a 15 reales. AHPS, PN, 86-194, 13-V-1584.

22 Un caso destacado es el de Martin Sanz Cadima, vecino de Gallinero, quien en 1555 vendió 2.001 arrobas a mercaderes burgaleses a $800 \mathrm{mrs}$., mientras Garcia de Medrano, señor de San Gregorio y miembro de un conocido linaje de la oligarquia soriana, tan sólo les vendia 688 arrobas. AHPS, PN, 34-90. Tambien hay que destacar a Hernando de Vinuesa, morador en San Andrés, aldea de la Tierra de Soria, quien en 1566 vendió a burgaleses 1.316 arrobas de lanas y 343 de aninos a 23 reales. AHPS, PN, 76-162, 14-VII-1566. Por su parte, Iñigo López de Salcedo, morador en La Póveda, vendió en 1586 a mercaderes de Vitoria lanas por valor de 7.000 ducados. AHPS, PN, 63-144. Todos estos ganaderos moradores en aldeas serranas de la Tierra de Soria mantenian vinculaciones familiares o de otro tipo con los grandes ganaderos integrados en la oligarquia, y en particular con los Vinuesa, que descendian de Gallinero. 
de Soria, habiendo ingresado en alguno de los 12 linajes de la ciudad y adquirido la propiedad de unas casas principales en la misma ${ }^{23}$.

La identidad de los propietarios medios resulta posible establecerla a partir de los contratos de venta de lanas extremeñas en los que intervienen cantidades situadas entre 100 y 1.000 arrobas por individuo, aunque a muchos de los que vendian cantidades superiores a las 500 arrobas se les podría identificar en varios sentidos como grandes propietarios, máxime teniendo en cuenta que para reunir esa cantidad se necesitarían en torno a 2.000 cabezas ${ }^{24}$.

Dadas las características de la documentación notarial soriana del XVI no resulta posible, a partir de su análisis, determinar el número aproximado de medianos propietarios ganaderos residentes en ámbitos rurales, pero al menos si se puede aventurar cuáles eran sus áreas de asentamiento preferente. $Y$ asi hemos podido advertir que la mayoria residian en aldeas serranas de la Tierra de Soria y de los señorios de Yanguas, San Pedro y Magaña, aunque también había algunos avecindados en aldeas de las tierras llanas ${ }^{25}$, y por supuesto en la propia ciudad de Soria, donde varios de los mercaderes laneros consta que también poseyeron sus propios rebaños ${ }^{26}$.

Teniendo en cuenta, pues, que entre los medianos propietarios coexistian individuos de variada condición sociopolítica, se advierte no obstante que la

${ }^{23}$ Cf. nota anterior. Tanto Hernando de Vinuesa como Iñigo López de Salcedo aparecen identificados frecuentemente como vecinos de Soria, aunque moradores en San Andrés y La Póveda.

24 Es el caso, por ejemplo, de García de Medrano, señor de San Gregorio y regidor de Soria, quien vendió a burgaleses 668 arrobas en 1555 (AHPS, PN, 34-90) y 709 arrobas de lana y 218 de aninos al año siguiente (Ibid., 25-60, 21-VIII-1556). También de Diego Ruiz de Ledesma, quien en 1571 vendió al mercader soriano Alonso Núnez 900 arrobas (Ibid., 78-176) y en 1573 vendió a un segoviano 403 arrobas (Ibid., 79-180). Es probable que estos contratos sólo afectasen a una parte del total de lanas esquiladas por él en cada año.

${ }^{25}$ Las referencias a ventas de lanas por productores medios son las más abundantes en los protocolos notariales de Soria, por lo que a extremeñas se refiere. Para no resultar excesivamente prolijos indicaremos que entre los vendedores figuran vecinos de Vinuesa, Derroñadas, La Póveda, Barriomartin, Gallinero, Cuéllar, Estepa de San Juan, Los Villares, Almajano, Paredesroyas, Velilla, Cabrejas del Campo, Bliecos, Sotillo, Buitrago, Castilfrio, La Losilla y otras aldeas de la Tierra de Soria. Las ventas de propietarios medios de la tierras de Yanguas y San Pedro Manrique suelen figurar en los protocolos notariales de estas dos villas. Como ejemplo, vid. la efectuada por Hernán Malo de Rio, vecino de Las Fuentes, aldea de San Pedro, al mercader yangüés Juan de Almarza de 400 arrobas de su ganado y del de sus aparceros en octubre de 1580 a 15 reales (AHPS, PN, 1752.4704).

${ }^{26}$ A principios del xvi estos mercaderes llegaron a ser incluso grandes propietarios, como Gabriel de Cuenca, que llegó a tener 20.000 cabezas con posesión en La Serena. Vid. Diago (1990a), p. 556. A fines del siglo Xvi se deja entrever una cierta recuperación del papel de los mercaderes como señores de ganados. Asi por la cuenta del pago de hierbas de La Serena de 1598-1599 consta que Domingo del Aguila y Pedro de Santa Cruz tenian conjuntamente 3.562 cabezas de posesion, y el primero además, por separado, 4.425 , que, no obstante, eran cifras muy 
mayor parte de ellos pertenecían a caracterizadas familias ganaderas de procedencia rural, que a la hora de concertar matrimonios manifestaban una evidente tendencia endogámica ${ }^{27}$. De hecho formaban parte del mismo sustrato social del que habían surgido los grandes ganaderos que se colocaron a la cabeza de las oligarquías de Soria y Agreda en el siglo XVI, los cuales también demostraron una idéntica preferencia por los matrimonios endogámicos ${ }^{28}$, pero a diferencia de éstos no lograron un enriquecimiento espectacular, debiendo conformarse por consiguiente con ocupar una posición preeminente sólo en sus aldeas de residencia ${ }^{29}$.

Por debajo de estos propietarios medios existian también en las comarcas serranas otros muchos pequeños propietarios, bastantes de los cuales no pueden ser identificados a partir de la documentación notarial de ventas de lanas porque frecuentemente vendian las suyas con los grandes señores. En los protocolos notariales de Yanguas abundan sin embargo en términos relativos contratos concertados por mercaderes de la villa con estos pequeños propietarios de aldeas de la comarca, en los que cada uno ponía a la venta cantidades de lanas extremeñas por regla general inferiores a las 100 arrobas ${ }^{30}$. Estos contratos no son tan frecuentes en los protocolos notariales de Soria, ciudad en la

alejadas de las 24.350 cabezas del señor de Almenar Antonio López de Rio y de las 23.912 de Alonso de Río. Vid. AHPS, PN, 139-481, 5-IX-1599.

27 Como modelo de contrato matrimonial entre familias ganaderas de rango medio y asentadas en ámbitos rurales vid. el concertado por Juan Duro, vecino de Vizmanos, aldea de la Tierra de Yanguas, para casar a su nieta, Juana González, con Bernardino de Sevilla, vecino de Vinuesa. Promete entregarle, entre otros bienes, en dote unas casas en Soria y 500 ovejas terciadas con su posesión en La Serena. AHPS, PN, 34-90, fol. 93, 3-X-1547.

${ }^{28}$ Basta recordar que los tres principales ganaderos del ámbito soriano a principios del xvi, Antón de Rio, Juan de Vinuesa y Diego González de Castejón, eran cuñados. Dentro del linaje Rios la tendencia a casar tios con sobrinas fue muy marcada a lo largo del siglo xvi y dio lugar a un notable proceso de acumulación de riqueza por concentración de mayorazgos.

29 La situación sociopolítica de las aldeas sorianas del xvi resulta todavía mal conocida por falta de dedicación de investigaciones monográficas. Parece que en algunas, como Vinuesa y Gallinero, las familias ganaderas llegaron a conformar una oligarquia bien definida. Esta situación se tradujo, por ejemplo, en la solicitud por Vinuesa en la década de 1580 del privilegio de villazgo, entonces sin éxito, y en la compra por parte del regidor soriano Juan de Vinuesa de la jurisdicción civil y criminal de Gallinero en 1564.

30 A título ilustrativo indicaremos que en AHPS, PN, 2755-4707 figuran los siguientes contratos de venta de lanas extremeñas a mercaderes de Yanguas correspondientes a 1582: 2 vecinos de Ledrado, 140 arrobas; 6 de Valloria y 1 de Vizmanos, 210; 1 de Santa Cecilia, 120; 5 de Vizmanos, 630; 1 de Matasejún, 40; 2 de Los Campos, 120; 3 de Villar de Maya, 260; 1 de Santa Cruz de Yanguas, 60; 1 de Las Aldehuelas, 10; 2 de Santa Cruz de Yanguas, 16; 1 de Los Campos, 50; 1 de Villaseca Somera, 20; 3 de Valloria, 60; 1 de Navavellida, 150; 1 de Villar de Maya, 320; 1 de Las Aldehuelas, 20; 1 de Vizmanos, 44. El contrato de mayor cuantía fue el concertado por dos hijos de Juan de Fuenmayor y de Maria de Cereceda, dos de las más caracterizadas familias ganaderas de Yanguas, que vendieron a Mateo de Almarza, criado del conde de Aguilar, 550 arrobas. 
que sus mercaderes negociaron preferentemente con medianos propietarios por un lado y con un sinfín de campesinos vendedores de pequeñas cantidades de lanas churras por otro ${ }^{31}$. Estos últimos estaban sin embargo ausentes del ámbito yangüés, donde las condiciones económicas de sobreabundancia de ganados y las propias condiciones climáticas imponían a todos los propietarios de ganados la opción de la trashumancia, al quedar vedado el aprovechamiento de los términos en invierno ${ }^{32}$. En las comarcas serranas de la Tierra de Soria parece que estos pequeños ganaderos trashumantes no se prodigaron tanto, sino que la inmensa mayoría de los que alli poseian pequeños rebanos eran mayorales o pastores, que nunca aparecian vendiendo independientemente sus lanas extremeñas.

En cualquier caso, por lo demás, estos pequeños propietarios de ganados trashumantes sólo resulta posible encontrarlos en comarcas serranas, y nunca en los ámbitos rurales de las tierras llanas, en los que, cuando había ganaderos trashumantes, éstos siempre pertenecían a familias relativamente acomodadas.

La pervivencia por otra parte de estos pequeños propietarios independientes en las últimas décadas del XVI, que fueron de crisis para el comercio lanero, pone de manifiesto que durante este siglo no tuvo lugar un irreversible proceso de decadencia de las pequeñas explotaciones trashumantes, que según Carande habrian conocido su mejor momento en la época medieval, pero a falta de datos cuantitativos seriables y precisos no podemos tampoco avanzar hipótesis sobre el papel que estas explotaciones tuvieron en la economía soriana de la época.

\section{GESTION DE LAS GRANDES EXPLOTACIONES GANADERAS TRASHUMANTES}

Las diferencias entre los grandes y pequeños propietarios ganaderos dedicados a la trashumancia en el ámbito soriano no sólo se traducían en el número de cabezas de sus rebaños, sino que también se detectaban de forma apreciable en la propia manera de gestionar las explotaciones ganaderas. Precisamente este tipo de explotaciones fueron las que en la Soria de la época estuvieron más directamente orientadas al mercado, y el análisis del régimen de gestión adoptado por algunos grandes ganaderos nos viene a poner de mani-

\footnotetext{
31 Vid. Diago (1992).

32 Según noticia de AGS, RGS, X-1511.
} 
fiesto una vez más cómo resulta desacertada la tesis que insiste en presentar a los ganaderos serranos como modestos propietarios que practicaron la trashumancia para adaptarse a las adversas condiciones climatológicas de sus tierras en invierno, pero no participaron del afán especulativo que animó a los terratenientes de nuevo cuño de ciudades y villas de las tierras llanas a invertir en ganados a lo largo del siglo XvI ${ }^{33}$.

Para empezar hay que acabar con la idea de que la institución mesteña trató de garantizar desde época medieval el acceso en régimen de igualdad de todos los pastores serranos al aprovechamiento de las dehesas de invernadero, y de que fueron los ganaderos riberiegos los que desde mediados del xvi dieron al traste con este régimen igualitario ${ }^{34}$. Hasta el reinado de los Reyes Católicos la inestabilidad política que conoció el reino de Castilla no favoreció la regularización del arrendamiento de estas dehesas, muchas de ellas controladas por maestres y comendadores de Ordenes Militares, pero a pesar de todo ya entonces había comenzado a consolidarse el privilegio de posesión, que alcanzaría su mayor efectividad a partir del momento en que la monarquia se hizo cargo de las mesas maestrales, las mayores propietarias de dehesas en la zona 35 .

El privilegio de posesión no garantizó sin embargo a todos los dueños de ganados de las sierras un acceso en régimen de igualdad a los pastos del sur, ni siquiera en las dehesas de las mesas maestrales, que eran aquellas en las que más se respetaba el referido privilegio, a diferencia de las que eran propiedad de caballeros particulares, que siempre se tendian a arrendar al mejor postor ${ }^{36}$. Por el contrario, y ateniéndonos al caso soriano, se observa que desde

33 Vid. Carande (1987), pp. 88-89. Sostiene que se pretendió al instituir la Mesta que muchos pastores pobres de las sierras encontrasen en las tierras bajas los pastos de los que carecian en invierno, y que este propósito quedó desvirtuado con la entrada de los riberiegos, que pasaron a ocupar la mayor parte de los pastos de Extremadura. Consideraciones sobre el terrateniente de nuevo cuño que invierte en ganados en el xvi y su contraste con los ganaderos modestos de la época anterior en Ruiz Martín (1974).

34 Vid. Carande (1987), pp. 77 y ss.

35 Vid. el arrendamiento de las dehesas de La Serena efectuado por los representantes de las cuadrillas de Soria y Yanguas en 1479 en AGS, PR, 11-93. Se estipula que si algún alcaide había vendido con anterioridad alguna dehesa que otros tuviesen en posesión, que la tal venta no sirviese. También se declararon nulas todas las obligaciones que en los años anteriores hubiesen hecho los pastores a los alcaides y otras personas «que tenian ocupada la Orden de Alcántara». Al tiempo se establece que las condiciones del arrendamiento afectaban en primer lugar a los que tuviesen posesión, y sólo después al resto de los hermanos de la Mesta «siempre que no se agravie a los que ya tienen posesión».

36 Asi se deduce del texto de un acuerdo de la Mesta adoptado en el Burgo de Osma en el verano de 1521 que reza: «Por quanto se ve el provecho que a nos los hermanos se sigue en el arrendamiento que se hace en las mesas maestrales juntamente todas las dehesas y viendo también el daño que se nos hace en el arrendamiento de las dehesas de los caballeros, comendado- 
el propio comienzo del reinado de los Reyes Católicos fueron unos pocos individuos - pertenecientes, entre otras, a las conocidas familias ganaderas de Ríos, Castejones, Vinuesas, Neilas y Calderones- los que monopolizaron las gestiones de arrendamiento de las dehesas de La Serena de la mesa maestral de Alcántara, que fueron las preferidas de los ganaderos sorianos, mientras en contrapartida los de Cuenca y Molina optaban por las de la mesa maestral de Calatrava ${ }^{37}$.

El valor que se asignaba en la primera mitad del Xvi por los ganaderos sorianos al disfrute de cabezas de posesión en La Serena es reconocido por los propios contemporáneos ${ }^{38}$, y de ahi que tanto en las ventas de ganados como en las dotes entregadas a doncellas de familias ganaderas figuren junto a las propias ovejas las correspondientes cabezas de posesión en la mesa maestral de Alcántara, que a veces eran incluso vendidas independientemente de las primeras 39 .

La constante presencia de las mismas familias en la negociación de los arrendamientos, que en el caso de los Rios procedentes de Yanguas y asentados en Soria a principios del XVI alcanzó cotas que apuntaban al monopolio ${ }^{40}$, no podía dejar detener su traducción en un progresivo acaparamiento

res y otras personas que entienden en dividir que cada uno se arriende por su cabom. AHN, Mesta, libro 500. La mayoria de los reclamos de posesión se refieren a dehesas pertenecientes a personas particulares. Sobre este asunto, vid. Marin Barriguete (1987).

37 Cf. nota 17. En el arrendamiento de 1479 (cf. nota 35) intervienen Pedro González del Rio y Diego de Castejón, vecinos de Yanguas, y Juan Calderón y Pedro de Neila, vecinos de Gallinero. Los que negociaron el arrendamiento de las dehesas de la mesa maestral de Alcántara en 1520 fueron Antón de Rio, hijo de Pedro González de Río, por si y por su cuñado Diego de Castejón, Juan de las Heras, Ruy Diez Calderón, Gabriel de Cuenca y otros varios vecinos de Vinuesa. Vid. AChV, PC, Taboada, F, envoltorio 146-10. En 1539 varios grandes señores de ganados del ámbito soriano otorgaron su poder a Martin González de Castejón, vecino de Agreda, y a Antón de Río para que arrendasen las referidas dehesas maestrales. AHPS, PN, antigua caja 5, 31 . VIII-1539.

${ }^{38}$ A titulo de ilustración se pueden citar las declaraciones de Gabriel de Cuenca, destacado señor de ganados de principios del xvi que tuvo bastantes cabezas de posesión en La Serena, in dicando cómo las posesiones de las mesas maestrales «valen mas que otras ningunas del reino porque son muy buenas y porque andan en justo y moderado precio mas que otras y porque son mas seguras y ciertas que ningunas del reino que son de caballeros y monasterios», $\mathrm{AChV}, \mathrm{PC}$ Taboada, F, envoltorio 146-10.

39. Según declaraciones de testigos, en la década de 1530 se valoraban las posesiones sin ovejas en 6 ó 7 reales, mientras que el precio de la oveja con posesión oscilaba entre ducado y 12 reales. Bastantes noticias a este respecto en $\mathrm{AChV}, \mathrm{PC}$, Taboada, F, envoltorio 146-10.

${ }^{40} \mathrm{Cf}$. nota 37. Hay que hacer constar también que Pedro González de Río, alcaide de Yanguas, fue tesorero y «hazedor" del maestrazgo de Alcántara. Vid. AGS, RGS, VII-1492, fol. 192 Su hijo Antón de Rio figura en la década de 1520 como «recebtor de los hervajes de las dehesas de la Serena», según documentación cit. en nota anterior. Por su parte, el hijo de éste, señor de Almenar y regidor de Soria, también llamado Antón de Río, fue el que en 1542 tomó a traspaso de Pedro González de León el arrendamiento del maestrazgo de Alcántara, que en años anteriores había estado en manos de los poderosos Fugger. Vid. Carande (1987), t. II, pp. 394-396 
de las cabezas de posesión en sus manos, que venía a garantizarles seguridad y economía en el importante capítulo de aprovisionamiento de pastos de invierno para sus ganados, dado que múltiples indicios demuestran que las dehesas maestrales eran más baratas y seguras que todas las demás ${ }^{41}$. De hecho era la propia riqueza e influencia política de los grandes posesioneros la que les proporcionaba su mejor baza a la hora de tener aseguradas para sus rebaños estas baratas dehesas, puesto que, según sugirió Carande, el aparato hacendístico de Carlos V, y luego también el de Felipe II, siempre estuvieron dispuestos a hacer todo tipo de concesiones a cambio de recibir préstamos ${ }^{42}$. Y no cabe duda de que los Ríos de Soria fueron unos de los que más partido supieron sacar de esta situación ${ }^{43}$.

En efecto la consulta de los pocos documentos en los que hasta ahora hemos encontrado datos cuantitativos contrastables sobre aprovechamientos de pastos en La Serena por los ganaderos sorianos nos ha confirmado la posición prepotente de los Ríos y otros grandes ganaderos entre los posesioneros de la mesa maestral de Alcántara. En concreto en el ejercicio de 1572-3 Alonso de Río, regidor de Soria, tuvo que pagar en torno al $25 \%$ del total que importaron aquel año las hierbas de La Serena - cerca de 3 millones de mrs. sobre un total de algo más de 11-, mientras que Juan Alonso de Vinuesa, señor de la merindad de Solpeña, su más inmediato seguidor, pagaba algo menos de millón y medio, Francisco López de Río pagaba $870.000 \mathrm{mrs}$. y el resto de los ganaderos cantidades inferiores al medio millón, situándose la más baja en 6.800 mrs. ${ }^{44}$.

Unas décadas más tarde, después de que Juan Alonso de Vinuesa hubiese vendido la mayor parte de su rebaño ${ }^{45}$, el predominio de los Ríos pasó a ser todavia mayor, y así nos lo confirma una distribución del pago de hierbas de La Serena del ejercicio $1598-9$, presumiblemente parcial e incompleta, pero su-

${ }^{41}$ Se reconoció expresamente en un memorial que en 1537 Alfonso Gutiérrez de Madrid presentó a la emperatriz y al Consejo Real sobre la necesidad de reajustar las rentas que los de la Mesta pagaban por las hierbas de los maestrazgos. Vid. Carande (1987), t. II, pp. 404 y ss.

42 Carande (1987), t. I, pp. 93 y ss.

43 La solvencia de Antón de Rio fue, por ejemplo, uno de los factores que más propiciaron el que se hiciese cargo del arrendamiento del maestrazgo de Alcántara en 1542, después de haber sido desplazados los Fugger. Así lo reconocieron los consejeros de hacienda cuando escribieron: «según el abono de la persona y hacienda de Antón del Rio parece que aquello está seguro». Vid. Carande (1987), pp. 395-396.

44 Vid. AHPS, PN, 79-180, 20-X-1573. Relación de dinero recibido por Martín Sanz Cadima el mozo, receptor de las hierbas de la mesa maestral de Alcántara.

45 Noticia sobre la venta que realizó a unos vecinos de Cuenca de ovejas por valor de 6.291.377 mrs. en AHPS, PN, 82-186, 4-X-1581. Este habia sido el heredero de su tío el regidor Juan de Vinuesa. 
ficientemente ilustrativa de cara a la caracterización de los Ríos como auténticos magnates ganaderos, puesto que nos revela que Alonso de Río tenía 23.912 cabezas de posesión por las que le correspondió pagar $2.348 .428 \mathrm{mrs}$, mientras que Antonio López del Río, señor de Almenar, le superaba con 24.350 cabezas, por las que le correspondió pagar 2.428 .359 mrs. ${ }^{46}$.

A la vista de estos datos, aun considerando que los grandes ganaderos admitirian en sus dehesas los rebaños de otros pequeños propietarios en régimen de aparceria, no parece del todo acertado hablar del desplazamiento en la segunda mitad del Xvi de los ganaderos serranos por parte de los riberiegos en el aprovechamiento de las dehesas de invernadero de la submeseta sur, cuando familias de ganaderos de indiscutible origen serrano, y que disfrutaron de notable influencia en las instituciones mesteñas de forma ininterrumpida desde la segunda mitad del siglo xv, llegaron a acumular en esa época más de 20.000 cabezas de posesión sólo en las dehesas correspondientes a una mesa maestral. Por el contrario, consideramos que tuvo lugar un proceso de concentración de riqueza ganadera en manos de unas cuantas familias serranas, que lograron acceder al aprovechamiento de los pastos del sur en condiciones privilegiadas, y que este fenómeno pudo tener repercusiones negativas sobre el resto de las explotaciones ganaderas trashumantes serranas, forzadas a buscar los pastos en dehesas más caras e inseguras o a entrar en dependencia de los grandes señores a través de los contratos de aparcería. En cualquier caso, este proceso de polarización en la distribución de la cabaña ganadera trashumante no se desarrolló a partir de una previa situación caracterizada por el reparto equitativo, puesto que las diferencias entre grandes y pequeños ganaderos trashumantes ya eran notables en el ámbito soriano en el siglo xv, aunque la falta de datos cuantitativos no permita probarlo con la precisión deseable.

Las dimensiones que alcanzó el proceso de acaparamiento de cabezas de posesión por parte de unos cuantos ganaderos entre los sorianos nos vienen por otra parte a reafirmar en la impresión de que las explotaciones ganaderas transhumantes de la Soria del siglo xvi llegaron a constituir en muchos casos auténticas empresas decididamente orientadas al mercado, por más que sus propietarios fuesen nobles que no consideraban la entrega personal a la práctica de los negocios como un hábito social encomiable. De hecho todos ellos contaron con el asesoramiento y colaboración de mayorales, encargados de asegurar buen cuidado a los rebaños, y hombres de negocios tanto de la ciu-

46 AHPS, PN, 139-481, 5-IX-1599. Sólo el arcipreste y vicario de Sepúlveda acumula mayor número de cabezas de posesión que los Rios de Soria, con 30.843. En el documento se distingue entre cabezas de precio mayor, mediano y menor, y quiebras. No hemos conseguido interpretar el significado de estos términos. 
dad de Soria como de fuera de ella, que tomaron bajo su responsabilidad todos los asuntos relacionados con los pagos, que en ocasiones podían llegar a ser notablemente complejos y farragosos ${ }^{47}$. No obstante, una novedad que presenta el siglo XVI en Soria con respecto al anterior radica en que todos estos grandes señores de ganados que vinieron a colocarse a la cabeza de su oligarquía - a diferencia de los caballeros hidalgos que dieron cuerpo a ésta en el siglo $\mathrm{XV}$, que concentraron la mayor parte de sus energias en actividades políticas y militares, en muchos casos al servicio de la monarquía - prestaron mayor atención a la gestión directa de sus haciendas. Y como ejemplo paradigmático se puede ofrecer el de los distintos representantes del linaje Ríos, que después de superada su relación de dependencia respecto a los condes de Aguilar a raiz de su traslado de residencia a Soria, centraron su actividad pública por un lado en la participación en las instituciones de gobierno de esta ciudad, defendiendo con frecuencia sus intereses como ganaderos y vendedores de lanas y corderos, y por otro en la intervención en las instituciones mesteñas, sin que en contrapartida conste que se preocupasen por desempeñar otros oficios al servicio de la burocracia imperial.

Sin duda este mayor interés por la gestión de sus haciendas, en un siglo inflacionista y en el que la política de endeudamiento de la monarquía contribuyó a conferir un carácter más mercantil a sus relaciones con las oligarquías urbanas, llevó a que las explotaciones ganaderas trashumantes en manos de la pequeña nobleza serrana tratasen de adaptarse a las exigencias de un mercado complejo, en el que junto a los factores estrictamente económicos también jugaban su papel los políticos y los hacendísticos, que resultaban de la confluencia de ambos.

Ya vimos cómo en el capítulo del arrendamiento de pastos de invernadero toda esta confluencia de factores llevó al reforzamiento de la posición de los grandes ganaderos sorianos. El análisis de otros capitulos con notable repercusión en el funcionamiento de las explotaciones ganaderas, como el de la regulación del aprovechamiento de los pastos de agostadero y el de la comercialización de las lanas y la carne, nos ha de llevar por su parte a la constatación de unos fenómenos semejantes. Pero dado que no hay aqui lugar para llevarlo a cabo con toda su amplitud, y que ello además exigiria el conocimiento en profundidad de ciertas cuestiones como la de la política del cobro de las alca-

47 Son habituales en los protocolos notariales las cartas de poder a mayorales para que arrienden dehesas en el sur. También en ellos se encuentran bastantes escrituras de poder a mercaderes y hombres de negocios de Soria o de Burgos para efectuar operaciones de cambio y pago en las ferias de Medina y Villalón y en otros lugares del sur. Un ejemplo de esta participación en la copia de un libro de cuentas del regidor Juan de Vinuesa en AChV, PC, Z. y Walls F. C. 585-1. 
balas, de las que por el momento estamos mal informados, simplemente nos vamos a limitar a llamar la atención sobre algunos puntos que hasta ahora nuestras investigaciones nos han permitido clarificar mejor.

En concreto por lo que se refiere al aprovechamiento de pastos de agostadero interesa ante todo hacer constar que, aun reconociendo que dentro del ámbito soriano en cada territorio jurisdiccional se planteaba el problema con sus propios matices, por regla general, y muy en particular en la Tierra de Soria, que constituia el ámbito jurisdiccional más extenso, imperó el régimen de libre acceso a los pastos en régimen de igualdad entre todos los vecinos, tanto del núcleo cabecera como de las aldeas dependientes ${ }^{48}$. No en todos los ámbitos serranos de Castilla dedicados a la trashumancia se practicó un régimen de tan extrema liberalidad, y de hecho el análisis del caso conquense proporciona un interesante contraste por cuanto alli ya desde el siglo XV proliferaron las dehesas de propiedad pública y particular, el arrendamiento de las cuales se disputaron ganaderos serranos por un lado y los grandes propietarios de las tierras llanas de pastos de invernadero por otro ${ }^{49}$. La enorme distancia que separaba las sierras sorianas de las comarcas de pastos de invernadero disuadiria a los grandes propietarios de rebaños sureños de llevarlos en verano hasta ellas, mientras que en contrapartida sólo ganaderos aragoneses demostraron cierto interés por los pastos estivales sorianos, que no dio lugar en cualquier caso a la llegada de numerosos ganados, pero que sí bastó para plantear enconados conflictos en la Tierra de Agreda en torno a la conveniencia de arrendar pastos 50 .

A pesar de todo, incluso los grandes señores de ganados de la Tierra de Soria se vieron obligados a tomar a renta el aprovechamiento de ciertos pastos de agostadero, tales como rastrojeras y dehesas de las aldeas ${ }^{51}$, aunque a la inversa también nos encontramos con que importantes ganaderos trashumantes cedian a renta los pastos de algunos de sus términos redondos, obteniendo importantes beneficios 52 . Es posible que se sucediesen coyunturas de abun-

48 Vid. Diago (1990a), pp. 278 y ss., $303-320$ y $473-483$.

49 Vid. Diago (1993a).

so Cf. nota 48.

51 Cf. nota 59. En los protocolos notariales de Soria hay varios ejemplos de contratos de arrendamiento de pagos, agostaderos y dehesas de aldeas por grandes ganaderos, entre los que figuran el regidor Juan de Vinuesa y el alférez mayor Francisco López del Rio. Las cantidades que debian pagar a los concejos aldeanos por este concepto solian ser bastante reducidas. (La más alta 22.000 mrs. pagados por Juan de Vinuesa al concejo de Segoviela en 1569.) Estos contratos se hacen más frecuentes a fines del siglo Xvi, quizá por el progresivo endeudamiento de los concejos rurales a consecuencia de la creciente presión fiscal de la monarquia.

52 Es el caso, por ejemplo, del licenciado Morales, oidor de la Chancilleria, al que el arrenda. miento de los «hervajes» de su término redondo de Malluembre le proporcionó en 1505 un total 
dancia y escasez que expliquen estas aparentes contradicciones, pero la tónica habitual fue que los ganaderos avecindados en las sierras sorianas, y en particular en la Tierra de Soria, tuviesen que gastar poco dinero para mantener sus rebaños en verano, y para que asi continuase sucediendo desplegaron toda su capacidad de presión sobre las instituciones de gobierno local que regulaban el aprovechamiento de pastos.

Junto al pago de los pastos otros varios conceptos figuraban en el capítulo de gastos de una explotación ganadera trashumante, desde las retribuciones de los pastores hasta el pago de los impuestos, pero las fuentes documentales que hemos utilizado no nos han permitido determinar el porcentaje de cada uno en el total. En contrapartida una averiguación de cuentas contenida en la documentación de un pleito nos informa que en la primera mitad del xvi los costes medios de una explotación ganadera trashumante soriana se evaluaban en torno a 2 reales y medio por cabeza, de forma que el mantenimiento de una cabaña de 3.000 cabezas vendría a costar $255.000 \mathrm{mrs}$. quedando de beneficios también una cantidad muy cercana a esta cifra 53 .

En concreto, al igual que el capítulo de gastos, el de ingresos estaba muy diversificado, si bien unas pocas grandes partidas respondían por la mayor parte de los mismos. Según la averiguación de cuentas a la que nos acabamos de referir, los principales conceptos por los que un ganadero obtenía ingresos eran los siguientes: lanas, aninos, quesos, pieles de ovejas muertas, ovejas viejas vendidas para carne y corderos 54 . En ella no se hace sin embargo mención a los carneros, y sin embargo los protocolos notariales y otras fuentes documentales demuestran que su comercio movia grandes cantidades de dinero, proporcionando elevadísimos ingresos a algunos grandes ganaderos, que garantizaban el aprovisionamiento no sólo de las carnicerías de Soria sino también de las de muchas otras ciudades del entorno, tanto del reino de Castilla como de los de Aragón, Navarra y Valencia ${ }^{55}$.

de $90.270 \mathrm{mrs}$. Vid. AChV, PC, Varela, F, C. 1673-2. Por fuentes documentales posteriores nos consta que entre los arrendatarios de Malluembre figuraban los campesinos del entorno. Vid. AHPS, PN, 23-53, 21-III-1549. El concejo de Ocenilla arrienda al señor de Malluembre una paridera de ganado en el término para aprovecharla desde abril hasta fin de agosto, por $6.000 \mathrm{mrs}$. anuales.

33 AChV, PC, Pérez Alonso, F. C. 1082-1.

54 Ibid. Las cifras parciales correspondientes a cada concepto eran las siguientes: lanas, $284.075 \mathrm{mrs}$; aninos, 35.200; quesos, 15.300; pieles de ovejas muertas, 9.078, y ovejas para carne, 15.827. El número de corderos para vender se estima en 1.200 , pero no se indica su valor. Vendidos al mismo precio que las ovejas viejas importarian $142.800 \mathrm{mrs}$.

"Según datos de un libro de cuentas del regidor Juan de Vinuesa, de $93.145 .881 \mathrm{mrs}$. que éste obtuvo en varios ejercicios de mediados del XVı de la venta de lanas y carneros, 20.151.030 mrs. correspondieron a este último producto. Entre sus compradores figuran mercaderes de Ná- 
La primacia indiscutible entre todas estas fuentes de ingresos la tenía sin embargo la venta de lanas, que representó sin ninguna duda el principal vínculo entre la actividad económica soriana y el mundo del gran comercio internacional y las altas finanzas desde el siglo Xv hasta principios del XIX. El análisis del régimen de comercialización de las lanas extremeñas en el ámbito soriano nos viene no obstante a poner de manifiesto una vez más que, en función de las diferentes condiciones en que los distintos señores de ganados accedian a este mercado lanero, la rentabilidad de las operaciones de venta variaba notablemente de unos casos a otros, resultando como siempre los más perjudica. dos los pequeños propietarios autónomos.

Los grandes señores de ganados vendian por regla general sus lanas a mercaderes foráneos, con los que frecuentemente entraban en contacto en las ferias de Medina y Villalón, en las que también se llevaban a efecto la mayor parte de las operaciones de pago. Aunque no parece probable que siempre vendiesen las lanas de un mismo ejercicio a un solo mercader, consta sin embargo que se comprometían habitualmente a la entrega de grandes cantidades por contrato, y todo ello exigía de los mercaderes el desembolso de enormes cantidades de dinero. Dados los problemas de liquidez que afectaban a estos mercaderes, lo habitual por consiguiente fue diferir el pago de las cantidades concertadas en los contratos, en ocasiones incluso varios años, marcando por lo regular como plazos de pago las ferias de Medina. Y esta circunstancia tuvo su necesaria traducción en la obtención por parte de estos grandes ganaderos de precios mucho más elevados para sus lanas, puesto que la situación de holgura financiera en que se desenvolvían les permitia embarcarse en encubiertas operaciones de crédito a la hora de negociar su venta ${ }^{56}$

Los compradores de estas grandes partidas de lanas extremeñas en las sierras sorianas fueron durante el siglo $\mathrm{XV}$ y gran parte del XVI en su gran mayoría vecinos de la ciudad de Burgos, que luego procedian a revenderlas en el mercado flamenco o en otros de la Europa atlántica. No obstante, desde fechas muy tempranas estuvieron también interesados por las lanas del ganado tras-

jera, La Guardia, Treviño, Navarrete, Logroño y Valencia. Vid. AChV, PC, Z. y Walls, F. C. 585-1. Los precios de los carneros presentan bastantes alternativas, y variaban en función de sus caracteristicas. (La gama de los precios constatados en documentos va de 22 reales a 14.) Entre otras grandes partidas podemos citar los 2.000 carneros ( 800 viejos y 1.200 borros) que en 1585 vendio el regidor Alonso de Río para las carnicerias de Soria. Vid. AMSo, actas, 18-II-1585. Algunos otros datos al respecto, en Diago (1990a), pp. 532-533.

56 A título de ejemplo ilustrativo indicaremos que en 1571, mientras el regidor Juan de $\mathrm{Vi}$ nuesa vendia a mercaderes burgaleses 4.224 arrobas de lana y 233 de aninos a $700 \mathrm{mrs}$. (AChV PC, Quevedo, F. C. 177-3) un pastor de Arguijo vendia 15 arrobas de lana también extremeña a tan sólo 476 mrs. (AHPS, PN, 46-113). 
humante soriano mercaderes de otras procedencias, tales como genoveses, riojanos o vascos ${ }^{57}$. $\mathrm{Y}$ en las últimas décadas del XVI todos estos últimos acabaron por desplazar de forma casi total a los vecinos de la ciudad del Arlanzón, que entró en una profunda crisis. La tendencia a exportar la mayor parte de las lanas extremeñas sorianas a los ámbitos atlánticos no obstante continuó, aunque se produjo un apreciable desplazamiento desde el ámbito flamenco hacia el francés, y excepcionalmente incluso también se efectuaron exportaciones a Italia. En cualquier caso los mercaderes y productores de paños sorianos apenas pudieron acceder a estas grandes partidas de lanas puestas en el mercado por los grandes señores de ganados de la comarca, teniéndose a veces que contentar a lo sumo con las de peor calidad, las únicas cuya compra podían financiar con los escasos medios de que disponían ${ }^{58}$.

Los medianos propietarios, que vendían por regla general menos de 500 arrobas por ejercicio, aunque en ocasiones al agruparse varios pudiesen superar con creces esta cantidad, solían entrar en contacto para la venta de sus lanas con mercaderes de segunda fila, asentados en Soria o en villas del entorno como Yanguas, que frecuentemente trabajaban como factores al servicio de mercaderes foráneos, aunque en ocasiones estos últimos también realizasen «expediciones» por las sierras sorianas para concertar directamente con ellos la compra de su producto ${ }^{59}$. Su relación con las ferias era, pues, menos intensa que la de los grandes ganaderos, aunque este punto convendría precisarlo mejor atendiendo a los datos de los libros de cuentas de mercaderes burgaleses, que diversos investigadores están trabajando en la actualidad. Pero ateniéndonos a los datos de los protocolos notariales sorianos podemos advertir que las condiciones de pago habitualmente concertadas por ellos eran diferentes, al resultar mucho más habituales en los contratos con medianos propietarios los adelantos de dinero efectuados por los mercaderes varios meses antes de la entrega de la mercancia, que tenían su reverso en la obtención de unos precios inferiores. $Y$ ya por fin estos adelantos, que a veces representaban auténticas operaciones de usura enmascaradas, alcanzaban su máxima representación en los contratos concertados con los pequeños propietarios ${ }^{60}$.

57 Datos a este respecto referidos al reinado de los Reyes Católicos en Diago (1989). Para el siglo xvi hemos recogido múltiples pruebas documentales en los protocolos notariales del AHPS. Con las mismas proyectamos elaborar un trabajo más exhaustivo sobre el comercio de lanas sorianas en el referido siglo, que complemente a Diago (1992).

58 Algunas referencias a esta cuestión, en Diago (1992). También en un articulo todavia inédito que hemos dedicado al análisis de la industria pañera soriana en el xvi. En todos los casos nos basamos en noticias documentales inéditas tomadas de los protocolos notariales de AHPS.

59 Esta práctica queda bien recogida en los protocolos notariales de la ciudad de Soria.

(1) Sobre los contratos con vendedores de pequeñas cantidades de lana churra, vid. Diago 
Como ya adelantamos, estos contratos con pequeños propietarios, a diferencia de todos los anteriores, sólo interesaron a mercaderes de segunda fila asentados en Soria y Yanguas, y en su mayoria no afectaban a lanas extremenas, procedentes del esquile del ganado trashumante, sino a lanas churras, obtenidas del esquile de los ganados estantes. Según demostramos en otro lugar, estas últimas eran de muy inferior calidad y precio, y se solian revender en su mayoria a productores de paños de los ámbitos soriano y camerano. Sólo en el ámbito serrano de la Tierra de Yanguas se prodigaron los contratos de venta de pequeñas cantidades de lanas extremeñas, adquiridas por mercaderes locales, que en su mayoría procedian a revenderlas a grandes mercaderes exportadores, aunque excepcionalmente llegasen en algunos casos a involucrarse directamente en empresas exportadoras ${ }^{61}$.

En suma, pues, el mercado de la lana se organizaba de una forma muy compleja en el ámbito soriano por cuanto en el mismo participaban tanto vendedores como compradores de muy diversa talla y capacidad financiera, aunque sin duda alguna quienes más ventaja económica sacaban de su posición eran por un lado los grandes señores de ganados que disponian de grandes cantidades para vender y podían diferir en el tiempo los cobros, y por otro lado los grandes mercaderes exportadores, que contaban con el respaldo financiero suficiente para arriesgarse en grandes operaciones de compra y reventa. $\mathrm{Y}$ en el otro lado de la moneda estaban por un lado los simples campesinos de las tierras llanas, que sólo podían vender unas cuantas arrobas de lana churra, y por otro los pequeños artesanos autónomos, que sólo alcanzaban a trabajar unas pocas arrobas en sus talleres. En posiciones intermedias estarían por fin los pequeños y medianos vendedores de lanas extremeñas y los mercaderes locales, proliferando no obstante entre todos ellos notables diferencias de rango.

\section{BIBLIOGRAFIA}

Argente des Castillo Ocaña, Carmen (1991): La ganadería medieval andaluza. Siglos XIIXVI (Reinos de Jaén y Córdoba), Jaén, 2 vols.

Asenjo Gonzalez, María (1990): «Las tierras de baldio en el concejo de Soria a fines de la Edad Media». Anuario de Estudios Medievales, 20, pp. 389-411.

Bishko, Charles J. (1981): «Sesenta años después: La Mesta de Julius Klein a la luz de la investigación subsiguiente». Historia. Instituciones. Documentos.

(1992). Para lo referente a pequeñas cantidades de lana extremeña, vid., entre otra, la documentación citada en notas 8 y 30 .

4 Diago (1992). 
Brumont, François (1984): «La laine dans la région de Najera (deuxième moitié du xviè siècle)m. Actas del II Coloquio de Metodología Histórica Aplicada. La documentación notarial y la historia, Universidad de Santiago, t. II, pp. 317-22.

Carande, Ramón (1987): Carlos V y sus banqueros, Barcelona, 3. a ed. 3 vols.

CORDOBA DE LA LlaVe, Ricardo (1989): La industria textil de Córdoba, Córdoba.

Diago Hernando, Máximo (1989): «El comercio de la lana en Soria en época de los Reyes Católicos». Celtiberia, 77-8, pp. 25-75.

(1990a): La Extremadura soriana y su ámbito a fines de la Edad Media, Universidad Complutense, Madrid.

(1990b): «Aprovechamiento de baldios y comunales en la Extremadura soriana a fines de la Edad Media». Anuario de Estudios Medievales, núm. 20, pp. 413-35.

- (1992): «El comercio de las lanas churras en el ámbito soriano durante el siglo XVI». Chronica Nova

(1993a, en prensa): «El arrendamiento de pastos en las comunidades de villa y Tierra a fines de la Edad Media». Agricultura y Sociedad.

— (1993b, en prensa): «Caballeros y ganaderos. Evolución del perfil socioeconómico de la oligarquía soriana en los siglos Xv y XvI». Hispania

Falah Hassan Abed Al-Hussein (1986). «Las ferias de Medina y el comercio de la lana: 1514-1573». Historia de Medina del Campo y su Tierra, Valladolid, vol. II, pp. 15-66.

KLEIN, Julius (1944): La Mesta, Madrid.

López Salazar Pérez, Jerónimo (1987): Mesta, pastos y conflictos en el Campo de Calatrava (siglo XVI), Madrid.

MARIN BARRIGUETE, Fermin (1987): La Mesta en los siglos XVI y XVI: roturaciones de pastos, cañadas, arrendamientos e impedimentos de paso y pasto, Universidad Complutense, $\mathrm{Ma}$ drid, 3 vols.

Ruiz MARTIN, Felipe (1974): «Pastos y ganaderos en Castilla: La Mesta (1450-1600)», en La lana come materia prima. I fenomeni della sua produzione e circolazione nei secoli XIII$X V I I$, Florencia.

RABAL, Nicolàs (1980): Historia de Soria, Soria.

\section{ABREVIATURAS}

AHPS Archivo Histórico Provincial de Soria

AMSo Archivo Municipal de Soria

PN Protocolos Notariales

AChV, P.C. Archivo de Chancillería de Valladolid,

F. Fenecidos 